\title{
Neuronal Activity of Histaminergic Tuberomammillary Neurons During Wake-Sleep States in the Mouse
}

\author{
Kazumi Takahashi, Jian-Sheng Lin, and Kazuya Sakai \\ Institut National de la Santé et de la Recherche Médicale U628, Université Claude-Bernard-Lyon I, 69373 Lyon Cedex 08, France
}

\begin{abstract}
Using extracellular single-unit recordings alone and in combination with neurobiotin juxtacellular labeling and histamine immunohistochemistry, we have identified, for the first time in nonanesthetized, head-restrained mice, histamine neurons in the tuberomammillary nuclei of the posterior hypothalamus. They are all characterized by triphasic broad action potentials. They are active only during wakefulness, and their activity is related to a high level of vigilance. During waking states, they display a slow $(<10 \mathrm{~Hz})$ tonic, repetitive, irregular firing pattern. Their activity varies in the different waking states, being lowest during quiet waking, moderate during active waking, and highest during attentive waking. They cease firing during quiet waking before the onset of EEG synchronization, the EEG sign of sleep (drowsy state), and remain silent during slow-wave sleep and paradoxical (or rapid eye movement) sleep. They exhibit a pronounced delay in firing during transitions from sleep to wakefulness or remain quiescent during the same transitions if the animals are not fully alert. They either respond with a long delay, or do not respond, to an arousing stimulus if the stimulus does not elicit an overt alert state. These data support the view that the activity of histaminergic tuberomammillary neurons plays an important role, not in the induction of wakefulness per se, but in the maintenance of the high level of vigilance necessary for cognitive processes. Conversely, cessation of their activity may play an important role in both the initiation and maintenance of sleep.
\end{abstract}

Key words: mouse; histamine neuron; neurobiotin; vigilance; extracellular single-unit recording; hypothalamus

\section{Introduction}

Since von Economo's anatomopathological observations on the viral encephalitic epidemic of 1918, several lines of experimental evidence have pointed to a crucial role of the posterior hypothalamus in the maintenance of wakefulness (W) (Moruzzi, 1972). Experimental destruction or inactivation of posterior hypothalamic neurons results in somnolence and hypersomnia. In addition, inactivation of these neurons restores sleep in various models of insomnia, produced either by destruction of the preoptic anterior hypothalamic area or by administration of drugs, such as para-chlorophenylalanine, a 5-hydroxytryptamine (serotonin or 5-HT) synthesis inhibitor, amphetamine, a psychostimulant, or modafinil, a newly discovered wake-promoting drug (Lin, 2000). Of the posterior hypothalamic neurons, the histaminergic neurons in the tuberomammillary nuclei (TM) are the sole source of neuronal histamine (HA) in the mammalian brain and are contained in widely branching neuronal pathways influencing large target fields, such as the noradrenergic neurons in the nucleus locus ceruleus and serotonergic neurons in the dorsal raphe nu-

Received June 2, 2006; revised Aug. 15, 2006; accepted Aug. 25, 2006.

This study was supported by Institut National de la Santé et de la Recherche Médicale U628, Claude Bernard University, and European Contract QLRT-2001-00826 (5th Programme cadre de recherche technologique). K.T. was supported by grants from the Fyssen Foundation. We thank Gérard Guidon for his expert technical assistance.

Correspondence should be addressed to Kazuya Sakai, Institut National de la Santé et de la Recherche Médicale U628, Université Claude-Bernard-Lyon 1, 8 Avenue Rockefeller, 69373 Lyon Cedex 08, France. E-mail: sakai@univ-lyon1.fr.

K. Takahashi's present address: Department of Physiology, Fukushima Medical University, Fukushima 960-1295, Japan.

DOI:10.1523/JNEUROSCI.2341-06.2006

Copyright $\odot 2006$ Society for Neuroscience $\quad 0270-6474 / 06 / 2610292-07 \$ 15.00 / 0$ cleus (DRN) (Schwartz et al., 1991; Wada et al., 1991; Haas and Panula, 2003). The HA system is therefore thought to play an important role in a wide variety of physiological functions, including sleep/waking regulation, learning, memory, attention, and control of affective states (Schwartz et al., 1991; Wada et al., 1991; Haas and Panula, 2003). HA neurons play an important role in the forebrain waking systems (Haas and Panula, 2003; Lin, 2000). Although much is known about the membrane properties of HA neurons in the rat posterior hypothalamus (Haas and Reiner, 1988; Greene et al., 1990; Haas, 1992; Llinas and Alonso, 1992; Stevens and Haas, 1996; Yang and Hatton, 1997), no information is available about the unit activity of identified HA neurons in vivo in general and across wake-sleep states in rodents, including the mouse in particular, despite its increasing use in experimental models. Determination of the activity of HA neurons across sleep-waking cycles is a prerequisite for an understanding of their precise roles in behavioral state control and of their physiological functions. Here we report for the first time that the unit activity of identified mouse HA neurons is waking specific and related to the high level of vigilance necessary for cognitive processes.

\section{Materials and Methods}

Animals and surgery. All experimental procedures followed European Economic Community Guidelines (86/609/EEC) and the Policy on Ethics approved by the Society for Neuroscience (1993). Every effort was made to minimize the number of animals used as well as any pain and discomfort.

Male adult C57BL/6 mice (28-35 g at the time of surgery; Harlan, Gannat, France) were used. Under pentobarbital anesthesia $(50 \mathrm{mg} / \mathrm{kg}$ 
i.p.), electrodes were implanted to record neocortical and hippocampal electroencephalograms (EEGs), neck muscle activity [electromyogram $(\mathrm{EMG})]$, and heart rate [electrocardiogram (EKG)]. For EEG recordings, screw electrodes were fixed in the frontal, parietal, and occipital cortices, and a stainless steel wire ( $200 \mu \mathrm{m}$ diameter, bare except for $0.5 \mathrm{~mm}$ at the tip) was implanted in the dorsal hippocampus. For EMG and EKG recordings, two stainless steel wires ( $250 \mu$ m diameter) were inserted in the neck muscles and one in the lateral chest. In addition, a U-shaped plastic plate (18 $\mathrm{mm}$ wide, $16 \mathrm{~mm}$ long, $5 \mathrm{~mm}$ thick) was fixed stereotaxically to the skull using dental acrylic cement so that the cranium could be painlessly returned to the same stereotaxic position using a semichronic head holder (SA-8; Narishige, Tokyo, Japan). A small hole was drilled in the skull above the posterior hypothalamus and covered by antibiotic cream for the subsequent insertion of microelectrodes. After a recovery period of 1 week, the animals were habituated to the head-restrained position by being placed on a cotton sheet inside a plastic box, painlessly restraining the head with a semichronic head holder and preventing large body movements with a cotton-coated plastic covering. During experiments, the head was covered to reduce visual stimuli. Under these conditions, the mice displayed complete sleep-waking cycles, consisting of W, slowwave sleep (SWS), and paradoxical [or rapid eye movement (REM)] sleep (PS) during all experiments lasting 6-8 h. During experiments, sugared water was regularly given through a fine tube attached to a syringe.

Extracellular single-unit and polygraphic recordings. Single neuronal activity was recorded extracellularly using a glass pipette microelectrode filled with either a $0.5 \mathrm{~m}$ sodium acetate solution containing $2 \%$ pontamine sky blue or $0.5 \mathrm{M} \mathrm{NaCl}$ containing $1.5 \%$ Neurobiotin ( $\mathrm{Nb}$; Vector Laboratories, Burlingame, CA). The electrode was vertically inserted in increments of 1-3 $\mu \mathrm{m}$ using a pulse motor microdrive manipulator (MO-81; Narishige, Tokyo, Japan). The neuronal activity was amplified and filtered (NeuroLog; Digitimer, Hertfordshire, UK) with a cutoff frequency of $100 \mathrm{~Hz}$ and then digitized at a sampling rate of $16.7-20.0 \mathrm{kHz}$ using a CED 1410 data processor (Cambridge Electronic Design, Cambridge, UK). The polygraphic signals were also digitized at a sampling rate of either 504 or $512 \mathrm{~Hz}$ and stored on a personal computer.

At the end of each experiment, pontamine sky blue was injected from the recording electrode by passing a negative current ( $5 \mu \mathrm{A}$ for $5 \mathrm{~min}$ ) so as to mark one or two recording sites in each electrode track.

Juxtacellular labeling with neurobiotin. $\mathrm{Nb}$ was dissolved at a concentration of $1.5 \%$ in $0.5 \mathrm{M} \mathrm{NaCl}$. When a single neuron was recorded across the sleep-waking cycle, $\mathrm{Nb}$ was delivered through the recording electrode with a 50\% duty cycle of $200 \mathrm{~ms}$ anodal current pulses of increasing intensity $(<10 \mathrm{nA})$ under continuous electrophysiological monitoring (Pinault, 1996). The pulse intensity was adjusted so as to modulate spontaneous firing without damaging the recorded neuron. The position of the microelectrode was also adjusted by moving the electrode with the hydraulic manipulator to prevent obvious cellular damage. Within $8 \mathrm{~h}$ after the end of $\mathrm{Nb}$ labeling, the mice received a lethal dose of pentobarbital and were processed for histochemistry.

Histochemistry. At the end of experiments, the animals were deeply anesthetized with pentobarbital and then perfused through the ascending aorta with $50 \mathrm{ml}$ of Ringer's solution, followed by $150 \mathrm{ml}$ of fixative consisting of $4 \% \mathrm{~N}$-(3-dimethylaminopropyl)-carbodiimide (CD; Sigma-Aldrich, Saint Quentin, France) in 0.1 M phosphate buffer (PB), $\mathrm{pH} 7.4$, followed by $100 \mathrm{ml}$ of $4 \%$ paraformaldehyde (PF). The brain was removed and postfixed for $48 \mathrm{~h}$ at $4^{\circ} \mathrm{C}$ in $\mathrm{PB}$ containing $4 \% \mathrm{CD}$ and $1 \%$ $\mathrm{PF}$ and placed in $\mathrm{PB}$ containing $30 \%$ sucrose for $48 \mathrm{~h}$ at $4^{\circ} \mathrm{C}$. Twenty micrometer sections were then cut on a cryostat and stored in $0.1 \mathrm{M}$ PBS containing $0.3 \%$ Triton X-100 (PBST) and $0.1 \%$ sodium azide until stained.

For juxtacellular $\mathrm{Nb}$ application experiments, the sections were first incubated overnight at $4^{\circ} \mathrm{C}$ with $\mathrm{ABC}$ (diluted 1:2000; Vector Laboratories) and then, after three rinses, were processed for visualization using $\mathrm{DAB}$ (Vector Laboratories) as chromogen. The sections were then incubated for $7-8 \mathrm{~d}$ at $4^{\circ} \mathrm{C}$ with rabbit anti-histamine antibodies (Millipore, Billerica, MA), diluted 1:80,000 in PBST. After several washes, the sections were incubated overnight at $4^{\circ} \mathrm{C}$ with biotinylated anti-rabbit IgG antibodies (Vector Laboratories), diluted 1:1000 in PBST. After several rinses, they were incubated for $90 \mathrm{~min}$ at room temperature with $\mathrm{ABC}$ (diluted 1:2000; Vector Laboratories) and then processed for visualization using DAB-nickel (Vector Laboratories) as chromogen.

Data analysis. Sleep-waking stages were defined using the EEG and neck EMG signals. W was defined as low-voltage, desynchronized EEG or $\theta$ waves accompanying sustained EMG activity. The drowsy state (D) was defined as the first $3 \mathrm{~s}$ period from the onset of EEG synchronization during the transition from W to SWS. SWS was defined by sustained high-voltage slow waves in the EEG and lowered EMG activity. PS was defined by sustained theta waves and decreased $\delta$ waves in the EEG and the absence of EMG activity. Power spectra were computed for $1 \mathrm{~s}$ epochs using a Fast Fourier Transform routine and the Spike2 analysis program (Cambridge Electronic Design). The lead from dorsal hippocampusoccipital cortex was usually used for the analysis of the $\delta(0.5-4.0 \mathrm{~Hz})$ and $\theta(6.0-12.0 \mathrm{~Hz})$ frequency bands. Analysis of unitary activity was performed using Spike2 software (Cambridge Electronic Design). Mean discharge rates were calculated from a total analysis time of $>10-30 \mathrm{~s}$ using $2-10 \mathrm{~s}$ bins for each of the following states: (1) attentive waking (AtW), elicited by touching the tail with a soft brush or removing the cover placed over the head of the mouse ( $5 \mathrm{~s}$ bin). This state is characterized by a low-amplitude (desynchronized) EEG with a sustained EMG activity; (2) active waking (AW), characterized by overt body, limb, or oral-buccal movements, including grooming (2-10 s bin); (3) quiet waking (QW), characterized by the absence of gross movements ( $3-10$ s bin); (4) drowsy state (3 s bin); (5) SWS (10 s bin); and (6) PS (10 s bin). The coefficient of variation for the firing interval ( $\mathrm{SD} /$ mean discharge interval) was calculated during the waking states. Statistical analysis was performed using one-way ANOVA or a two-tailed $t$ test, a $p$ value of $<0.05$ or 0.01 being considered, respectively, as significant or highly significant.

\section{Results}

Extracellular recordings were made from a total of 181 neurons in the TM region of the posterior hypothalamus of 17 mice during the complete sleep-wake cycle, including at least one episode of PS. The present report is mainly based on a homogenous group of 42 neurons recorded in the TM (Figs. 1, right side, $2 a$ ). In the rat brain, the TM has been subdivided into either three (medial, ventral, and diffuse) (Ericson et al., 1987) or five (E1-E5) (Inagaki et al., 1988) subgroups. As shown in Figure 1 (left side), the HA neurons were also found in these regions in the mouse posterior hypothalamus. In the mouse TM, we found a strikingly homogeneous group of neurons that were clearly distinguished from other posterior hypothalamic neurons in terms of spike shape, firing rate, and firing pattern across the sleep-waking cycle and in response to an arousing sound stimulus. They were judged to be HA neurons on the basis of their characteristic action potential waveform, their spontaneous discharge pattern across the sleep-waking cycle, and their double immunostaining with juxtacellularly applied $\mathrm{Nb}$ and $\mathrm{HA}$, as described below.

\section{General characteristic of HA TM neurons}

All HA TM neurons displayed a broad, triphasic action potential (Fig. 3A). The HA TM neurons could be clearly distinguished in terms of wave form from other posterior hypothalamic neurons, which exhibited either narrow (Fig. 3B1) or broad (Fig. 3B2) biphasic action potentials, such as those of "waking-active" neurons (see below).

All HA TM neurons discharged tonically during W and fell completely silent during both SWS and PS (Fig. 4) and are hereafter referred to as "waking-specific" neurons. During waking states, characterized by desynchronized EEG or theta waves, they displayed a slow $(<10 \mathrm{~Hz})$ tonic, repetitive, irregular firing pattern, as shown by the large $(>0.5)$ coefficients of variation for the spike interval (supplemental Table 1, available at www.jneurosci. org as supplemental material). As shown in Figure 5 and summa- 


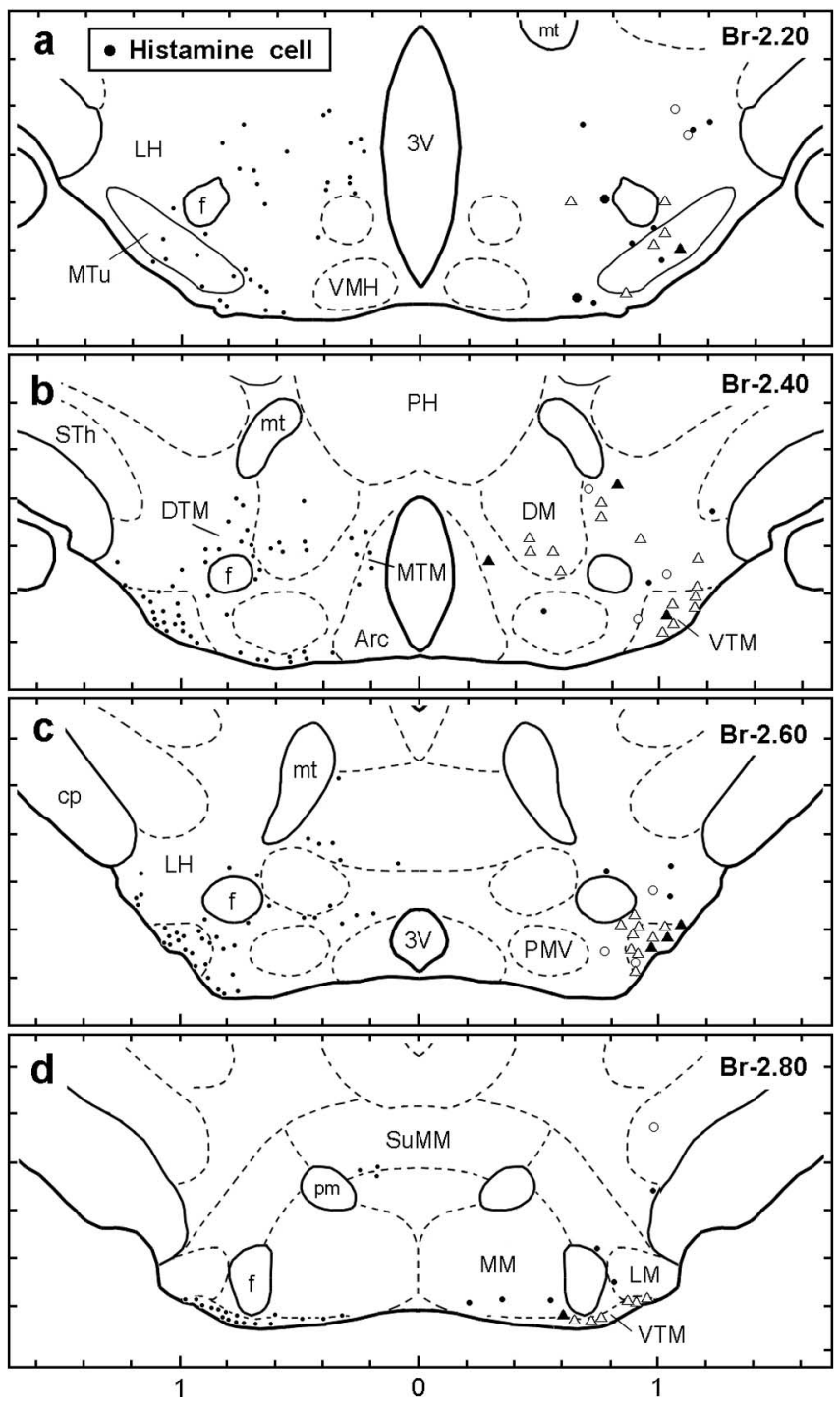

Figure 1. Camera lucida drawings of frontal sections (four different planes at $0.2 \mathrm{~mm}$ intervals rostral to caudal) showing the distribution of $\mathrm{HA}$-immunoreactive neurons (dots on the left side) and that of waking-specific neurons (white and black triangles on the right side), wakingactive neurons (white and black circles on the right side), and other $\mathrm{Nb}$-labeled non-HA neurons (dots on the right side). The white triangles and circles indicate cells from which recordings were made but which were not tested for Nb labeling and subsequent identification of neurotransmitter content. The black triangles indicate waking-specific neurons labeled with both $\mathrm{Nb}$ and $\mathrm{HA}$. The black circles indicate waking-active neurons labeled with $\mathrm{Nb}$ but immunonegative for HA. 3V, Third ventricle; Arc, arcuate nucleus; $\mathrm{Br}$, bregma; $\mathrm{cp}$, cerebral peduncle; DM, dorsomedial hypothalamic nucleus; DTM, diffuse tuberomammillary nucleus; MTM, medial tuberomammillary nucleus; VTM, ventral tuberomammillary nucleus; $f$, fornix; MM medial mammillary nucleus; LM, lateral mammillary nucleus; mt, mammillothalamic tract; MTu, medial tuberal nucleus; PH, posterior hypothalamic area; pm, principal mammillary tract; PMV, ventral premammillary nucleus; STh, subthalamic nucleus; SuMM, medial supramammillary nucleus.

rized in supplemental Table 1 (available at www.jneurosci.org as supplemental material), the activity of these neurons varied in the different waking states, being lowest during QW without motor behavior (Mean $\pm \mathrm{SD}, 3.00 \pm 1.21$ spikes/s), moderate during AW with motor activities (4.12 \pm 1.42 spikes/s), and highest during AtW (5.15 \pm 1.99 spikes/s) elicited by touching the tail with a soft brush or removal of the cover placed over the mouse. The difference in firing rate for the three states was statistically highly significant $(F=16.21, p<0.001)$. A significant difference in discharge rate was also seen between AtW and AW and between AW and QW ( $p<0.05$, two-tailed $t$ test $)$.
In addition to the 42 waking-specific HA TM neurons, we found 12 waking-active TM neurons, which discharged at a higher rate during waking, at a lower rate during the drowsy state and SWS, and at the lowest rate during PS (Fig. 1, indicated by circles on the right side, and Fig. $6 A, B$ ). The discharge rate and firing pattern of these waking-active neurons were variable, and none displayed complete cessation of discharge during sleep, thus differing from the HA TM waking-specific neurons. Their mean discharge rates \pm SD during AW, QW, SWS, and PS were $5.97 \pm$ $5.09,2.76 \pm 1.57,0.86 \pm 1.04$, and $0.30 \pm 0.25 \mathrm{~Hz}$, respectively.

\section{Change in unit activity during state transitions}

We then examined changes in unit activity of the waking-specific neurons during behavioral state transitions. During the transition from $\mathrm{W}$ to SWS (Fig. 7A, $\mathrm{t} 2$ ), they stopped discharging before the onset of EEG synchronization, the first sign of EEG sleep (drowsy state), with a mean ( \pm SEM) latency of $1078.3 \pm 72.7 \mathrm{~ms}$ (range, 450.2-3016.0). During the transition from SWS to W (Fig. $7 A, \mathrm{t} 1$ ), they displayed firing not before, but after, the onset of EEG desynchronization, with a mean latency of $800.18 \pm 62.7$ ms (range, 318.6-2099.6). It should be mentioned that, when the animals entered a steady sleep cycle consisting of multiple SWS and PS episodes, brief interruptions of sleep caused by phasic body movements were not accompanied by any spike discharge (Fig. 4, arrowheads on the hypnogram). During the transition from PS to W (Fig. 7A, t3), they exhibited unit discharges soon after the end of the PS episode, defined by the interruption of sustained theta waves and the onset of EEG desynchronization (see also Fig. 4). The mean latency to onset of the spike discharge from the end of PS was 3849.2 $\pm 833.8 \mathrm{~ms}$ (range, 223.9-24893.0).

\section{Response to an arousing sound stimulus}

When applied during SWS, an arousing sound stimulus (hand clapping) elicited a change in the EEG pattern from synchronization to desynchronization (Fig. 7B). HA TM neurons either responded to the stimulus with a pronounced delay (mean minimal latency \pm SEM, $384.5 \pm 81.1 \mathrm{~ms}$; range, 57.0-1941.5) (Fig. 7B, 1) or did not respond at all (latency, $>2 \mathrm{~s}$ ), especially when the stimulus did not elicit a steady state of EEG desynchronization or $\theta$ waves, the sign of alertness (Fig. 4, indicated by arrows with "s," and Fig. $7 B, 2)$. The mean minimal latency ( \pm SEM) for wakingactive neurons was $105.3 \pm 26.6 \mathrm{~ms}$ (range, 14.1-313.1), significantly shorter $(p<0.01$, two-tailed $t$ test) than that of wakingspecific neurons.

\section{Juxtacellular labeling by $\mathrm{Nb}$ and double immunostaining}

Successful recordings across all sleep-wake states were made from 28 neurons, which were then labeled with $\mathrm{Nb}$ and found to be located in the TM region of the posterior hypothalamus (Fig. 1, right side). Eight were HA immunopositive (Fig. 2b), and all eight were waking-specific neurons, characterized by a triphasic broad action potential. The remaining 20 neurons were HA immunonegative (Fig. 2c), and all were characterized by a biphasic action potential. Of these, 2 were $\mathrm{W}$-active, 6 were W/PS-active, 5 were SWS/PS-active, and 7 were state indifferent (Fig. 1).

\section{Discussion}

The present study is the first to investigate single-unit discharge of HA TM neurons in nonanesthetized, head-restrained mice across wake-sleep states. We have identified, for the first time in vivo, HA neurons in the TM nuclei of the posterior hypothalamus and found that they are active only during $\mathrm{W}$ and that their 


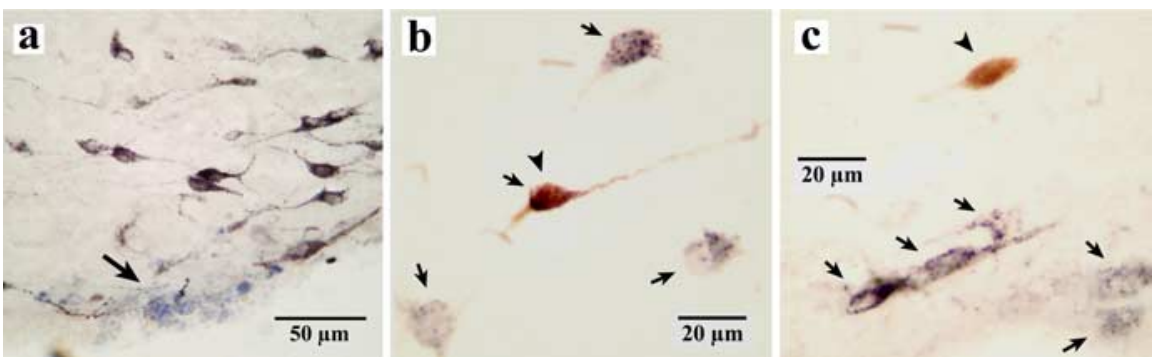

Figure 2. HA and non-HA neurons marked with pontamine sky blue or labeled for HA in the TM. $\boldsymbol{a}$, Photomicrographs showing the recording site of a waking-specific neuron marked with pontamine sky blue in the ventral TM. $\boldsymbol{b}, A$ waking-specific neuron stained with both $\mathrm{Nb}$ and $\mathrm{HA}$ (arrows and arrowhead). c, A non-waking-specific neuron labeled only with Nb (arrowhead). $\boldsymbol{b}, \boldsymbol{c}$ Arrows indicate neurons stained only with HA. The arrow in a shows the recording site of a waking-specific neuron in the ventral tuberomammillary nucleus marked with pontamine sky blue. all subgroups of the TM in which HA neurons are found, but not in other regions of the posterior hypothalamus. These mouse TM neurons exhibited a characteristic spike shape and a remarkably homogeneous pattern of unit activity in different behavioral states and in response to an arousing stimulus, as discussed below. Double immunostaining with $\mathrm{Nb}$ and $\mathrm{HA}$ showed that the waking-specific neurons characterized by a triphasic broad action potential were indeed HA positive, whereas other types of neurons with either a narrow or broad biphasic action potential were HA negative.

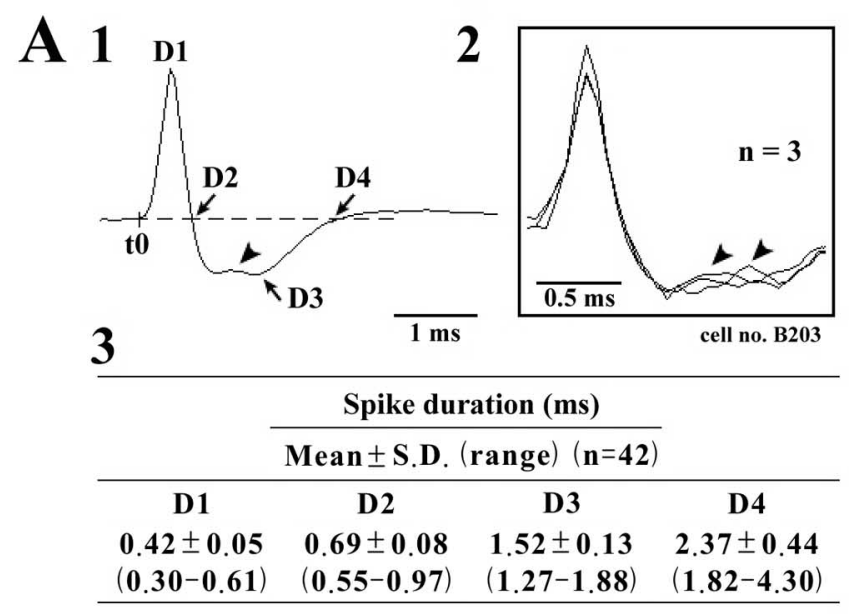

B 1

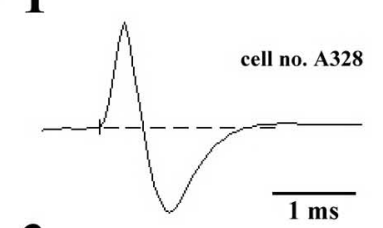

2

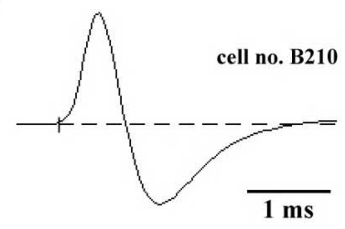

3

\begin{tabular}{cccc}
\hline & \multicolumn{3}{c}{ Spike duration $(\mathrm{ms})$} \\
\cline { 2 - 3 } & Mean \pm S.D. $($ range $)(\mathrm{n}=12)$ & \\
\hline D1 & D2 & D3 & D4 \\
$0.35 \pm 0.07$ & $0.57 \pm 0.12$ & $0.94 \pm 0.20$ & $1.80 \pm 0.42$ \\
$(0.30-0.55)$ & $(0.42-0.85)$ & $(0.67-1.21)$ & $(1.39-2.79)$
\end{tabular}

Figure 3. $\quad \boldsymbol{A}, \boldsymbol{B}$, Spike shape of waking-specific $(\boldsymbol{A})$ and waking-active $(\boldsymbol{B})$ neurons. Note that waking-specific neurons are characterized by a broad triphasic action potential, whereas waking-active and other TM neurons are characterized by a biphasic (either narrow or broad) action potential. The arrowheads in $\mathbf{A} \mathbf{1}$ and $\mathbf{A} \mathbf{2}$ indicate the positive deflection. $\ln \mathbf{A}$ and $\mathbf{B} \mathbf{3}$, $D 1-D 4$ indicate the duration of the averaged action potential measured from onset $(\mathrm{t} 0)$ to the peak (D1), the first zero crossing (D2), the peak of the afterhyperpolarization (D3), and the second zero crossing (D4), shown in $\boldsymbol{A}$.

activity is related to a high level of vigilance. They cease firing during the drowsy state characterized by a low vigilance level and remain quiescent during the transition from sleep to $\mathrm{W}$ when the animals are not fully alert and respond with a long delay, or do not respond at all, to an arousing stimulus if it does not elicit an overt alert state. Several lines of evidence support the view that these waking-specific neurons are all HA. They were recorded in

\section{Characteristics of HA TM neurons in vitro and in vivo}

All mouse TM waking-specific neurons had a broad triphasic action potential. This finding is consistent with those previously obtained by in vitro intracellular recording from identified HA TM neurons in the rat brain (Haas and Reiner, 1988; Greene et al., 1990; Kamondi and Reiner, 1991; Llinas and Alonso, 1992; Reiner and Kamondi, 1994; Stevens et al., 2001).

In brain slice preparations, most HA TM neurons are reported to fire spontaneously at a slow-regular rate $(0.5-10 \mathrm{~Hz})$ at the resting membrane potential (Stevens et al., 2001). In urethaneanesthetized rats, HA TM neurons are reported to discharge slowly, with a relatively regular pattern (Reiner and McGeer, 1987). In the present in vivo experiments in nonanesthetized, head-restrained mice, HA TM neurons were completely quiescent during both the drowsy state and sleep, and, during waking states, displayed a tonic $(<10 \mathrm{~Hz})$ but irregular firing pattern, as shown by the large coefficient of variation for the spike interval $(\mathrm{CV}>0.5)$, suggesting that mouse HA TM neurons are very sensitive to changes in vigilance level and various synaptic inputs. In this regard, mouse HA TM neurons differ from those in the cat and dog, in which presumed HA TM neurons are reported to fall silent only during deep SWS and PS (Vanni-Mercier et al., 1985; Sakai et al., 1990; John et al., 2004). Steininger et al. (1999) recently reported the presence of PS (REM)-off neurons in the rat posterior hypothalamus, including the ventrolateral subgroup of the TM. These neurons appear to be similar to the waking-active neurons described in the present study but differ from HA TM waking-specific neurons in terms of their location, biphasic spike shape, and reduced but persistent discharge during SWS and PS. In the present study, two waking-active neurons were labeled with $\mathrm{Nb}$, and both were found to be HA negative.

Role of HA neurons in the control of sleep-wake regulation Three HA receptors, $\mathrm{H}_{1}, \mathrm{H}_{2}$, and $\mathrm{H}_{3}$, have been identified in the brain. $\mathrm{H}_{1}$ and $\mathrm{H}_{2}$ receptors mainly mediate excitatory postsynaptic actions, whereas $\mathrm{H}_{3}$ receptors, located on histaminergic and other cell somata, dendrites, and axons, cause autoinhibition of HA TM neurons and inhibition of the release of other neurotransmitters (Haas and Panula, 2003). $\mathrm{H}_{1}$ receptors mediate excitatory actions on whole brain activity, and systemic administration of $\mathrm{H}_{1}$ receptor antagonists, commonly known as antihistamines, evokes sedation in humans (Nicholson, 1983; Schwartz et al., 1991). Our previous study showed that local injection of muscimol in the TM causes sleep (Lin et al., 1989), suggesting a role of HA TM neurons in the sedation and sleep.

Neuropeptides, named orexins (Orx) [also called hypocretins (Hcrt)], have been discovered in the posterior hypothalamus and 


\section{Waking-specific neuron}

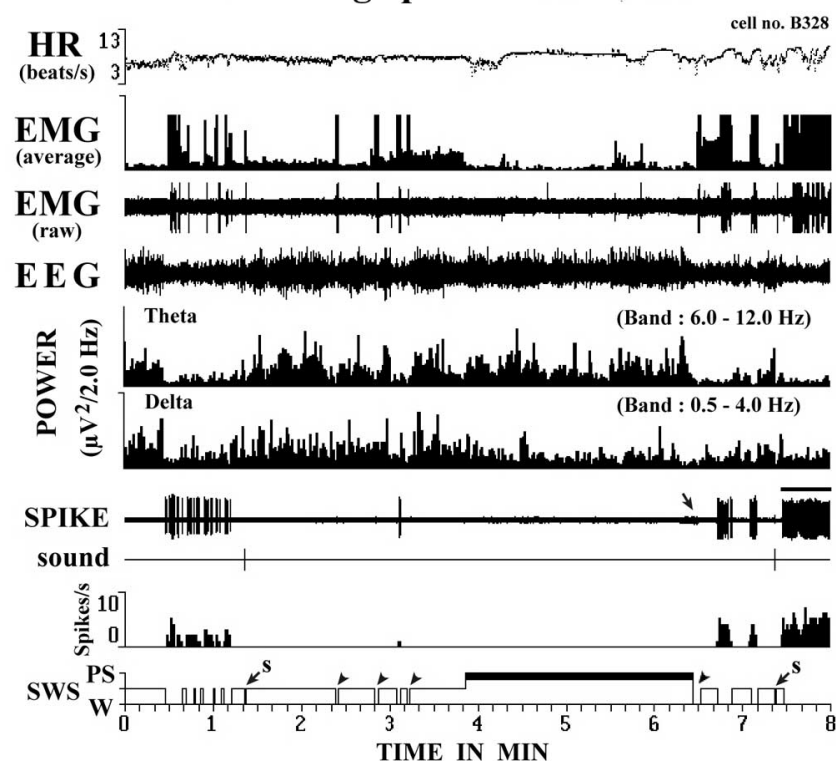

Figure 4. Activity of a representative waking-specific neuron. Note that activity is confined to waking periods, with the cell being completely silent during sleep. Note also the absence of discharge during short awakening periods (arrowheads) during sleep. The large arrow indicates the end of PS, as shown by the interruption of theta waves and the onset of EEG desynchronization. The small arrows with an " $s$ " indicate short awakenings elicited by the arousing sound stimulus.

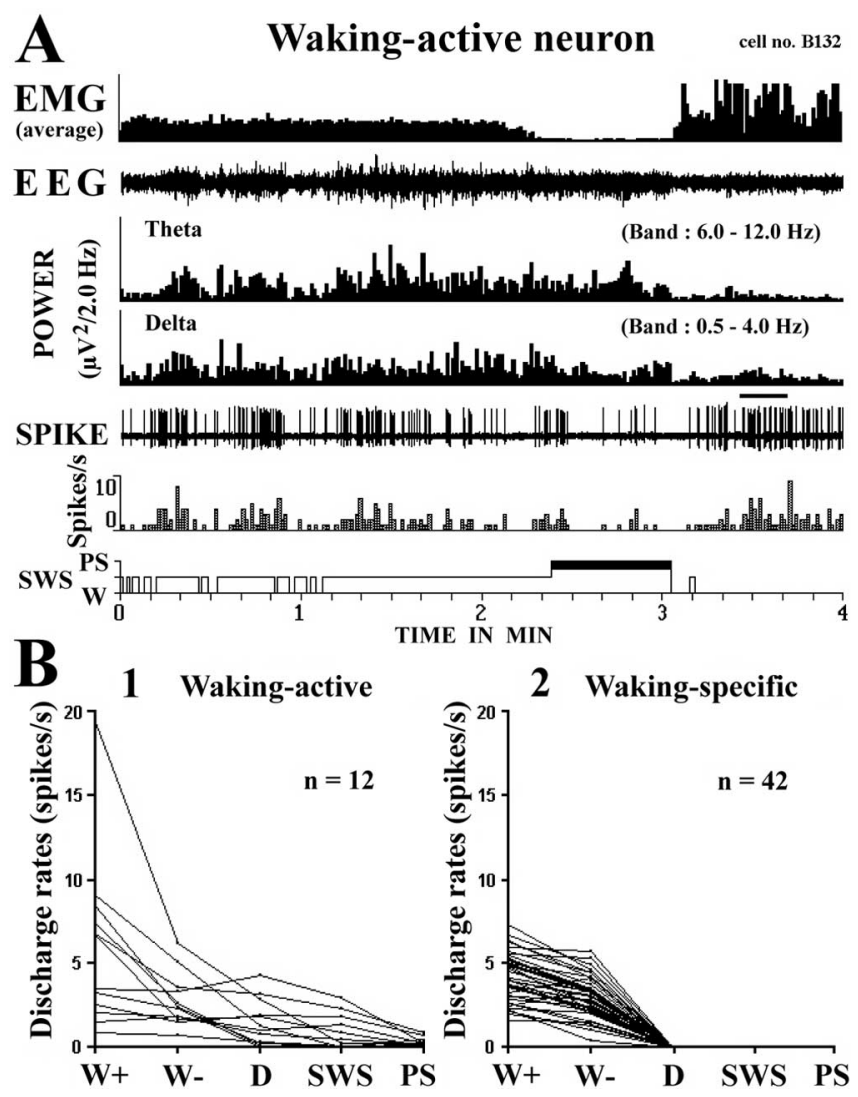

Figure 6. $\quad \boldsymbol{A}, \boldsymbol{B}$, Activity of a representative waking-active neuron $(\boldsymbol{A})$ and discharge profile of waking-active (B1) and waking-specific (B2) neurons across the sleep-waking cycle.

are reported to play a role in the mechanisms of wake-sleep regulation and in the pathophysiology of narcolepsy/cataplexy (Chemelli et al., 1999; Lin et al., 1999; Peyron et al., 2000). Orx/ Hcrt directly excites HA TM neurons in vitro in rat brain slice preparations (Bayer et al., 2001; Eriksson et al., 2001; Yamanaka et al., 2002). Recent in vivo studies in mice showed that intracerebroventricular infusion of orexin A selectively activates the HA system (Hong et al., 2005) and causes a significant increase in W in wild-type mice but not in $\mathrm{H}_{1}$ receptor gene knock-out mice (Huang et al., 2001), suggesting that the arousal effect of orexin A is mainly mediated by activation of the HA system.

In the present experiments in mice, all HA TM neurons fell silent during quiet waking before the onset of EEG synchronization observed during the drowsy state, suggesting that the cessation of activity of HA TM neurons may play a role in the induction of SWS. The mechanisms underlying this cessation of activity during sleep are not known, but it is currently believed that it is caused by GABAergic inputs from sleep-active neurons in the preoptic and basal forebrain areas (Saper et al., 2001). During the transition from sleep to $\mathrm{W}$ or in response to an arousing stimulus during sleep, there was a marked delay in the onset of firing of HA TM neurons. It has been shown in vitro (Haas and Reiner, 1988; Greene et al., 1990; Llinas and Alonso, 1992; Stevens et al., 2001) that, when depolarizing pulses are applied from a hyperpolarized membrane potential level, there is a long delay before activation of cells because of a pronounced voltagegated transient outward current (A-type current) (Connor and Stevens, 1971). It is possible that mouse HA TM neurons are hyperpolarized during sleep and that the transient outward current ensures that the membrane potential remains below thresh-
Figure 5. Activity of a representative waking-specific neuron during the different waking states. 


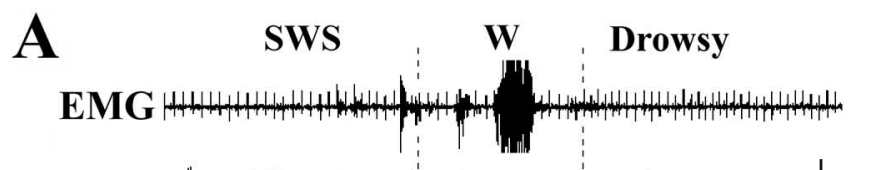

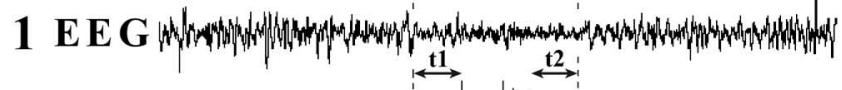

Unit

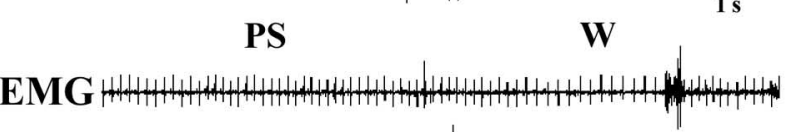

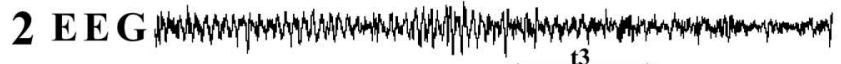
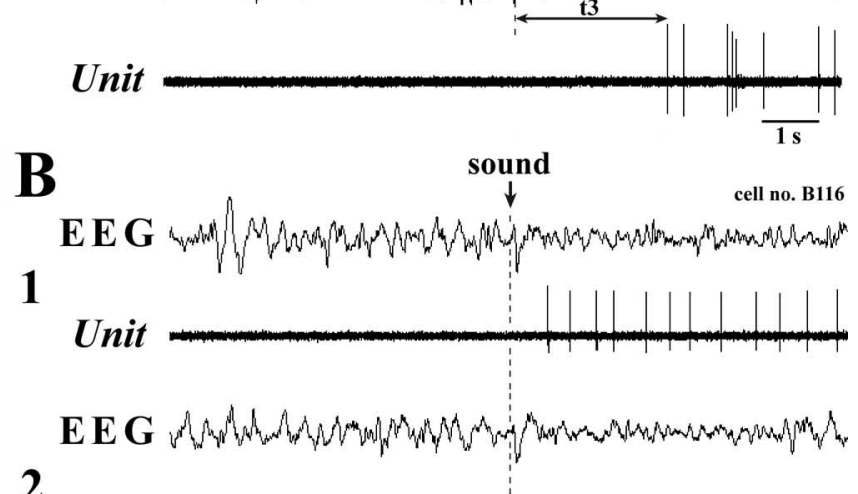

2

Unit

$1 \mathrm{~s}$

Figure 7. $\quad A, B$, Discharge pattern of a waking-specific neuron during behavioral state transitions $(\boldsymbol{A})$ and response to an arousing sound stimulus $(\boldsymbol{B}) . \operatorname{In} \boldsymbol{A}$, the transition from SWS to $W$ is shown as $t 1$, that from $W$ to drowsy state is shown as t2, and that from PS to $W$ is shown as $t 3$. Note that the unit fires with a long delay after the onset of EEG desynchronization of W, whereas it stops firing during quiet waking before the onset of the drowsy state, defined by EEG synchronization. Note also that there is no, or a long-delayed, response to a sound stimulus given during sleep.

old during sleep. Cessation of activity of HA TM neurons may therefore play a role in the maintenance of sleep.

As shown in the present study, HA TM neurons display arousal-specific neuronal activity. Although the activity of human HA TM neurons remains unknown, presumed HA TM neurons in cats and dogs are reported to display a highly arousalspecific neuronal activity similar to that seen in mice (VanniMercier et al., 1985; Sakai et al., 1990; John et al., 2004). An increase in histaminergic transmission enhances $\mathrm{W}$, whereas its blockade causes somnolence (for review, see Lin, 2000). HA induces a switch in neuronal firing mode from rhythmic burst to single spike activity in thalamic relay neurons (McCormick and Williamson, 1991) and an increase in spiking by reducing spikefrequency adaptation (McCormick and Williamson, 1989). In addition, HA stimulates cholinergic neurons of the brainstem and basal forebrain (Khateb et al., 1995; Lin et al., 1996; Crochet and Sakai, 1999; Koyama and Sakai, 2000) and serotonergic neurons of the DRN (Sakai and Crochet, 2000; Brown et al., 2002), both implicated in waking and attention. Collectively, these data indicate an important role of HA in the control of arousal.

In the present study, HA TM neurons ceased firing during the drowsy state, characterized by a low vigilance level, remained quiescent during the transition from sleep to $\mathrm{W}$ when the animals were not fully alert, and responded with a long delay, or dis not respond at all, to an arousing stimulus if it did not elicit an overt alert state. These findings suggest that the activity of HA TM neurons plays an important role not in the induction of W per se, but in the maintenance of a high level of vigilance, and that lack of HA neuronal activity results in somnolence. These data are in good agreement with those of our recent study showing that $\mathrm{KO}$ mice for histidine decarboxylase, the HA-synthesizing enzyme, display a deficit in $\mathrm{W}$ and signs of somnolence when faced with a novel environment (Parmentier et al., 2002). Additional detailed studies in freely behaving animals are required to determine whether or not a particular waking state drives the neuronal activity of HA TM neurons or vice versa. The alternation between waking and sleep is determined by multiple arousal- and sleeppromoting systems, which are widely distributed in the brain (Jones, 2005). Precise knowledge of the unit activity profiles of these systems during the state transition should be helpful to understand how each system contributes to the generation and/or maintenance of the behavioral states.

In conclusion, the present study shows, for the first time in mice, that HA neuronal activity is specific to the waking state with a high vigilance level and that these neurons may play a role not in the initiation of W per se, but in the maintenance of the high level of vigilance necessary for cognitive processes. Conversely, cessation of their activity may play an important role in both the initiation and maintenance of sleep.

\section{References}

Bayer L, Eggermann E, Serafin M, Saint-Mleux B, Machard D, Jones B, Mühlethaler M (2001) Orexins (hypocretins) directly excite tuberomammillary neurons. Eur J Neurosci 14:1571-1575.

Brown RE, Sergeeva OA, Eriksson KS, Haas HL (2002) Convergent excitation of dorsal raphe serotonin neurons by multiple arousal systems (orexin/hypocretin, histamine, and noradrenaline). J Neurosci 22:8850-8859.

Chemelli RM, Willie JT, Sinton CM, Elmquist JK, Scammell T, Lee C, Richardson JA, Williams SC, Xiong Y, Kisanuki Y, Fitch TE, Nakazato M, Hammer RE, Saper CB, Yanagisawa M (1999) Narcolepsy in orexin knockout mice: molecular genetics of sleep regulation. Cell 98:437-451.

Connor JA, Stevens CF (1971) Voltage clamp studies of a transient outward membrane current in gastropod neural somata. J Physiol (Lond) 213:21-30.

Crochet S, Sakai K (1999) Effects of microdialysis application of monoamines on the EEG and behavioural states in the cat mesopontine tegmentum. Eur J Neurosci 11:3738-3752.

Ericson H, Watanabe J, Köhler CH (1987) Morphological analysis of the tuberomammillary nucleus in the rat brain: delineation of subgroups with antibody against L-histidine decarboxylase as a marker. J Comp Neurol 263:1-24.

Eriksson KS, Sergeeva O, Brown RE, Haas HL (2001) Orexin/hypocretin excites the histaminergic neurons of the tuberomammillary nucleus. J Neurosci 21:9273-9279.

Greene RW, Haas HH, Reiner PB (1990) Two transient outward currents in histamine neurons of the rat hypothalamus in vitro. J Physiol (Lond) 420:149-163.

Haas H, Panula P (2003) The role of histamine and the tuberomamillary nucleus in the nervous system. Nat Rev 4:121-130.

Haas HL (1992) Electrophysiology of histamine receptors. In: The histamine receptor (Schwartz JC, Haas HL, eds), pp161-177. New York: Wiley.

Haas HL, Reiner P (1988) Membrane properties of histaminergic tuberomammillary neurons of the rat hypothalamus in vitro. J Physiol (Lond) 399:633-646.

Hong ZY, Huang ZL, Qu WM, Eguchi N (2005) Orexin A promotes histamine, but not norepinephrine or serotonin, release in frontal cortex of mice. Acta Pharmacol Sin 26:155-159.

Huang ZL, Qu WM, Li WD, Mochizuki T, Eguchi N, Watanabe T, Urade Y, Hayaishi O (2001) Arousal effect of orexin A depends on activation of the histaminergic system. Proc Natl Acad Sci USA 98:9965-9970.

Inagaki $\mathrm{N}$, Yamatodani $\mathrm{A}$, Ando-Yamamoto $\mathrm{M}$, Tohyama $\mathrm{M}$, Watanabe $\mathrm{T}$, Wada H (1988) Organization of histaminergic fibers in the rat brain. J Comp Neurol 273:283-300. 
John J, Wu MF, Boehmer LN, Siegel JM (2004) Cataplexy-active neurons in the hypothalamus: implications for the role of histamine in sleep and waking behavior. Neuron 27:619-634.

Jones BE (2005) Basic mechanisms of sleep-wake states. In: Principles and practice of sleep medicine (Kryger MH, Roth T, Dement WC, eds), pp 136-153. Philadelphia: Elsevier.

Kamondi A, Reiner PB (1991) Hyperpolarization-activated inward current in histaminergic tuberomammillary neurons of the rat hypothalamus. J Neurophysiol 66:1902-1911.

Khateb A, Fort P, Pegna A, Jones BE, Muhlethaler M (1995) Cholinergic nucleus basalis neurons are excited by histamine in vitro. Neuroscience 69:495-506.

Koyama Y, Sakai K (2000) Modulation of presumed cholinergic mesopontine tegmental neurons by acetylcholine and monoamines applied iontophoretically in unanesthetized cats. Neuroscience 96:723-733.

Lin JS (2000) Brain structures and mechanisms involved in the control of cortical activation and wakefulness, with emphasis on the posterior hypothalamus and histaminergic neurons. Sleep Med Rev 4:471-503.

Lin JS, Sakai K, Vanni-Mercier G, Jouvet M (1989) A critical role of the posterior hypothalamus in the mechanisms of wakefulness determined by microinjection of muscimol in freely moving cats. Brain Res 479:225-240.

Lin JS, Hou Y, Sakai K, Jouvet M (1996) Histaminergic descending inputs to the mesopontine tegmentum and their role in the control of cortical activation and wakefulness in the cat. J Neurosci 16:1523-1537.

Lin L, Faraco J, Li R, Kadotani H, Rogers W, Lin X, Qiu X, de Jong PJ, Nishino S, Mignot; E (1999) The sleep disorder canine narcolepsy is caused by a mutation in the hypocretin (orexin) receptor 2 gene. Cell 98:365-376.

Llinas RR, Alonso A (1992) Electrophysiology of the mammillary complex in vitro. I. Tuberomammillary and lateral mammillary neurons. J Neurophysiol 68:1307-1320.

McCormick DA, Williamson A (1989) Convergence and divergence of neurotransmitter action in human cerebral cortex. Proc Natl Acad Sci USA 86:8098-8102.

McCormick DA, Williamson A (1991) Modulation of neuronal firing mode in cat and guinea pig LGNd by histamine: possible cellular mechanisms of histaminergic control of arousal. J Neurosci 11:3188-3199.

Moruzzi G (1972) The sleep-waking cycle. Ergeb Physiol 64:1-165.

Nicholson AN (1983) Antihistamines and sedation. Lancet 2:211-212.

Parmentier R, Ohtsu H, Djebbara-Hannas Z, Valatx JL, Watanabe T, Lin JS (2002) Anatomical, physiological, and pharmacological characteristics of histidine decarboxylase knock-out mice: evidence for the role of brain histamine in behavioral and sleep-wake control. J Neurosci 22:7695-7711.

Peyron C, Faraco J, Rogers W, Ripley B, Overeem S, Charnay Y, Nevsimalova S, Aldrich M, Reynolds D, Albin R, Li R, Hungs M, Pedrazzoli M, Padi- garu M, Kucherlapati M, Fan J, Maki R, Lammers GJ, Bouras C, Kucherlapati R, et al. (2000) A mutation in a case of early onset narcolepsy and a generalized absence of hypocretin peptides in human narcoleptic brains. Nat Med 6:991-997.

Pinault D (1996) A novel single-cell staining procedure performed in vivo under electrophysiological control: morpho-functional features of juxtacellular labeled thalamic cells and other central neurons with biocytin or Neurobiotin. J Neurosci Meth 65:113-136.

Reiner PB, Kamondi A (1994) Mechanisms of antihistamine-induced sedation in the human brain: $\mathrm{H} 1$ receptor activation reduces a background leakage potassium current. Neuroscience 59:579-588.

Reiner PB, McGeer EG (1987) Electrophysiological properties of cortically projecting histamine neurons of the rat hypothalamus. Neurosci Lett 73:43-47.

Sakai K, Crochet S (2000) Serotonergic dorsal raphe neurons cease firing by disfacilitation during paradoxical sleep. NeuroReport 11:3237-3241.

Sakai K, El Mansari M, Lin JS, Zhang JG, Vanni-Mercier G (1990) The posterior hypothalamus in the regulation of wakefulness, and paradoxical sleep. In: The diencephalon and sleep (Mancia M, Marini M, eds), pp 171-198. New York: Raven.

Saper CB, Chou TC, Scammell TE (2001) The sleep switch: hypothalamic control of sleep and wakefulness. Trends Neurosci 24:726-731.

Schwartz JC, Arrang JM, Garbarg M, Pollard H, Ruat M (1991) Histaminergic transmission in the mammalian brain. Physiol Rev 71:1-51.

Steininger TL, Alam MN, Gong H, Szymusiak R, McGinty D (1999) Sleepwaking discharge of neurons in the posterior lateral hypothalamus of the albino rat. Brain Res 840:138-147.

Stevens DR, Haas HL (1996) Calcium-dependent prepotentials contribute to spontaneous activity in rat tuberomammillary neurons. J Physiol (Lond) 493:747-754.

Stevens DR, Eriksson KS, Brown RE, Haas HL (2001) The mechanism of spontaneous firing in histamine neurons. Behav Brain Res 124:105-112.

Vanni-Mercier G, Sakai K, Jouvet M (1985) Waking-statespecific neurons in the posterior hypothalamus of the cat. Sleep 84:238-240.

Wada H, Inagaki N, Yamatodani A, Watanabe T (1991) Is the histaminergic neuron system a regulatory center for whole-brain activity? Trends Neurosci 14:415-418.

Yamanaka A, Tsujino N, Funabashi H, Honda K, Guan JL, Wang OP, Tominaga M, Goto K, Shioda S, Sakurai T (2002) Orexins activate histaminergic neurons via the orexin 2 receptor. Biochem Biophys Res Commun 2002:1237-1245

Yang QZ, Hatton GI (1997) Electrophysiology of excitatory and inhibitory afferents to rat histaminergic tuberomammillary nucleus neurons from hypothalamus and forebrain sites. Brain Res 773:162-172. 